\title{
Morphologic and Morphometric Analysis of Hepatozoon spp. (Apicomplexa, Hepatozoidae) of Snakes
}

\author{
Tatiana Cristina Moço, Lucia Helena O'Dwyer/ ${ }^{+}$, Fabiana Custódio Vilela*, \\ Thomaz Henrique Barrella*, Reinaldo José da Silva
}

\author{
Departamento de Parasitologia, Instituto de Biociências, Unesp, Distrito de Rubião Júnior s/nº , 18618-000 Botucatu, SP, Brasil \\ *Centro de Estudos de Venenos e Animais Peçonhentos, Unesp, SP, Brasil
}

\begin{abstract}
Hepatozoon species are the most abundant hemoparasites of snakes. Its identification has been based mainly on the morphologic characterization of the gamonts in the peripheral blood of the vertebrate host and also of the cysts found in the internal organs of the vertebrate and invertebrate hosts. Using a computerized image analysis system, we studied five species of Hepatozoon from recently captured snakes in Botucatu, State of São Paulo, Brazil, to evaluate the importance of the morphology and morphometry of the gamonts for the characterization of Hepatozoon species and to analyze the morphologic changes induced in the erythrocytes by the parasite. The studied species were $\mathrm{H}$. terzii of Boa constrictor amarali, Hepatozoon sp. of Crotalus durissus terrificus, H. philodryasi of Philodryas patagoniensis, and $\mathrm{H}$. migonei and $\mathrm{H}$. cyclagrasi of Hydrodynastes gigas. We observed three different groups, one of them including the species $\mathrm{H}$. terzii, $\mathrm{H}$. philodryasi and Hepatozoon sp. of $\mathrm{C}$. durissus terrificus; and the other two consisting of $\mathrm{H}$. migonei and $\mathrm{H}$. cyclagrasi. Degree of alterations in the erythrocytes was variable and it may be useful for characterization of Hepatozoon species.
\end{abstract}

Key words: Hepatozoon - parasites - snakes - morphometry - morphology - erythrocytes

Hepatozoon species are the most abundant hemoparasites of snakes (Wozniak et al. 1994). Many Hepatozoon species have been described among Brazilian snakes: H. juxtanuclearis (Carini 1947, Pessoa 1967), H. fusifex (Ball et al. 1969) and H. terzii (Sambon 1909) parasites of Boa constrictor, $H$. romani and $H$. capsulata (Phisalix 1931) parasites of Crotalus durissus terrificus, H. philodryasi (Carini 1910) parasite of Philodryas patagoniensis, H. migonei (Arantes 1934, Schouten 1934, Pessoa et al. 1970) and H. cyclagrasi (Pessoa et al. 1970) parasites of Hydrodynastes gigas.

Identification of Hepatozoon species has been based mainly on the morphologic characterization of the gamonts in the peripheral blood of the vertebrate host and also of the cysts found in the internal organs of the vertebrate and invertebrate hosts. However, these stages are very similar for the different species of Hepatozoon, and so the identification based only on these characteristics may be incorrect (Pessoa \& De Biasi 1973, Pessoa et al. 1973).

The main reports of Brazilian snake Hepatozoon give information on the morphology of the gamonts (shape, stain, and capsule presence) and also provide morphometric data usually consisting of the description of the length and width of the gamonts and cysts. In recent works, using computerized image analysis systems, measurements of the parasite and nucleus areas have been

Financial support: Fundação de Amparo a Pesquisa do Estado de São Paulo.

${ }^{+}$Corresponding author. Fax: +55-14-6821.3744. E-mail: odwyer@ibb.unesp.br

Received 16 January 2002

Accepted 6 September 2002 also reported (Silva et al. 1999). Morphometric analysis allows a more detailed evaluation of cellular morphology, including linear and area measurements.

Morphological descriptions of most Hepatozoon species of Brazilian snakes are of fundamental importance to contribute to the knowledge of this group of parasites. A complete morphological description of a Hepatozoon species should include morphological and morphometric features of all stages of the parasite, including the sporogonic stages in the arthropod vector.

The objective of the present investigation was to study species of Hepatozoon in recently captured snakes from Botucatu, State São Paulo, Brazil, to evaluate the importance of morphology and morphometry for the characterization of the species, and to analyze the morphologic alterations induced in the erythrocytes by the presence of the parasite.

\section{MATERIALS AND METHODS}

Snakes and blood collection - Parasites of four snake species from Botucatu, São Paulo, Brazil, were studied. The animals were donated to the Center for the Study of Venoms and Venomous Animals of São Paulo State University and presented Hepatozoon on the occasion of the first blood examination. Blood was collected from all snakes by ventral tail venipuncture and blood smears were prepared immediately upon collection. Smears were air dried, fixed with absolute methanol for $3 \mathrm{~min}$ and stained with $10 \%$ Giemsa for $30 \mathrm{~min}$. The slides were microscopically surveyed for hemoparasites by light microscopy at $250 \mathrm{x}$ magnification.

The studied hosts and parasites were:

Boa constrictor amarali (Boidae) - The following species have been described for this snake: H. juxtanuclearis, H. fusifex, and H. terzii (Sambon 1909, Carini 1947, Pessoa 1967, Ball et al. 1969). The species H. juxtanuclearis (Carini 
1947) and H. fusifex (Ball et al. 1969) are morphologically different from the species studied in the present investigation that is $H$. terzii (Sambon 1909). The gamonts of H. terzii are club-shaped organisms with the anterior end broad and rounded, the posterior extremity tapering slightly to a blunt point and folded back hookwise for a length of about $3 \mu \mathrm{m}$. They are enclosed within capsules measuring $14 \mu \mathrm{m}$ in length and $4 \mu \mathrm{m}$ in breadth. The nucleus measure $3 \mu \mathrm{m}$ in length by $4 \mu \mathrm{m}$ in breadth, and is usually placed in the posterior half of the body. A variable number of deeply-staining granules are commonly present in the cytoplasm on either side of the nucleus (Sambon 1909).

Philodryas patagoniensis (Colubridae) - The only species described for this snake is $H$. philodryasi (Carini 1910). This species measures 11-13 $\mu \mathrm{m}$ in length and 2-3.5 $\mu \mathrm{m}$ in width. The parasitized erythrocytes are not changed by the parasites and the nucleus maintains its normal position (Carini 1910).

Hydrodynastes gigas (Colubridae) - Two Hepatozoon species have been described in the literature: a small one, H. migonei (Arantes 1934, Schouten 1934, Pessoa et al. 1970), and a large one, H. cyclagrasi (Pessoa et al. 1970). H. migone $i$ is a parasite which presents $12-14 \mu \mathrm{m}$ in length and 3-3.5 $\mu \mathrm{m}$ in breadth (Arantes 1934, Schouten 1934, Pessoa et al. 1970). H. cyclagrasi is reported as an abnormal form, with large cytoplasm, with "swollen" and "spongy" aspect, and it induces enlargement of the erythrocyte and displacement of nucleus for one of the cell poles. The parasite can measure up to 35-40 $\mu$ m length (Pessoa et al. 1970).

Crotalus durissus terrificus (Viperidae) - The following species have been described in the literature: $H$. romani and $H$. capsulata (Phisalix 1931). H. romani measures $17-18 \mu \mathrm{m}$ in length and $8.4 \mu \mathrm{m}$ in width. The nucleus measures $2-3 \mu \mathrm{m}$ and was not condensed. $H$. capsulata measures $16.8 \mu \mathrm{m}$ in length and $6.3 \mu \mathrm{m}$ in width. The nucleus measures $4.2 \mu \mathrm{m}$ and was condensed (Phisalix 1931). The Hepatozoon studied in present investigation was not similar to any of the described species and therefore we considered it as Hepatozoon sp.

Morphologic and morphometric analyses - For each Hepatozoon species we analyzed the shape of the gamont, the presence of pigment in the cytoplasm, and the format and position of its nucleus. Morphometric analysis was performed using the KS-300 computerized image analysis system (Zeiss) at 1000x magnification. The analyzed variables were: area, length and width of the parasite, and area, length and width of the nucleus of the parasite. A total of 100 parasites were analyzed for each infected snake. We also analyzed 100 normal erythrocytes and 100 infected erythrocytes in terms of the following variables: area, length and width of the erythrocyte, and area, length and width of the nucleus of the erythrocyte.

Statistical analysis - Data obtained for the parasites were compared by analysis of variance, by the StudentNewman-Keuls test and by multivariate analysis. Data for infected and non-infected erythrocytes were compared by the $t$ test. All statistical tests were performed using the Sigma Stat 2.0 and MVSP 3.1 software, with the level of significance set at $5 \%$.

\section{RESULTS}

Morphologic analysis of the parasites

Boa constrictor amarali $-H$. terzii presented an elongated and slender shape, with a cellular area of $35.3 \pm 4.1$ $\mu \mathrm{m}^{2}$; the length was $14.6 \pm 0.4 \mu \mathrm{m}$ and the width $2.6 \pm 0.4$ $\mu \mathrm{m}$. The cytoplasm was slightly stained with no granulations. The nucleus was homogeneous, dense and parallel to the larger axis of the parasite. In $57.3 \%$ of the parasites the nucleus was slightly displaced towards one of the extremities and in $42.7 \%$ it was in a central position. The area of the nucleus was of $9.2 \pm 1.6 \mu \mathrm{m}^{2}$, the length was $4.6 \pm 0.9 \mu \mathrm{m}$ and the width $2 \pm 0.3 \mu \mathrm{m}$ (Fig. 1A). Some erythrocytes were infected with more than one parasite.

Crotalus durissus terrificus - The Hepatozoon sp. studied presented an elongated and slender shape. Its cellular area was of $33.2 \pm 4.1 \mu \mathrm{m}^{2}$, the length was $14.7 \pm$ $0.6 \mu \mathrm{m}$ and the width $2.4 \pm 0.4 \mu \mathrm{m}$. The cytoplasm was lightly stained and homogeneous. The nucleus was homogeneous, dense, and parallel to the longer axis of the parasite. In $51.5 \%$ of the parasites the nucleus was lightly displaced towards one of the extremities and in $48.5 \%$ it was in a central position. Its area was $8.5 \pm 1.7 \mu \mathrm{m}^{2}$, its length $5.1 \pm 0.8 \mu \mathrm{m}$ length and its width $1.7 \pm 0.4 \mu \mathrm{m}$ (Fig. 1B).

Philodryas patagoniensis - H. philodryasi presented an elongated and slender shape, with a cellular area of $37.5 \pm 7.2 \mu \mathrm{m}^{2}$, a length of $14.3 \pm 1.1 \mu \mathrm{m}$ length and a width of $2.8 \pm 0.5 \mu \mathrm{m}$. Its cytoplasm was homogeneous and lightly stained. The nucleus was homogeneous, dense and parallel to the larger axis of the parasite. In $93.7 \%$ of the parasites the nucleus was lightly displaced toward one of the extremities and in $6.3 \%$ it was in a central position. Its area was of $9.6 \pm 1.8 \mu \mathrm{m}^{2}$, its length $5.2 \pm$ $0.8 \mu \mathrm{m}$ and its width $2.0 \pm 0.4 \mu \mathrm{m}$ (Fig.1C). More than one gamont infecting the same erythrocyte was usually found in this host.

Hydrodynastes gigas - This snake presented two different parasites: (1) H. cyclagrasi, a large parasite almost occupying the entire cytoplasm of the erythrocyte, presented an elongated and wider shape. Its cellular area was $115.2 \pm 11.8 \mu \mathrm{m}^{2}$, its length $21.7 \pm 1.4 \mu \mathrm{m}$ and its width $6.4 \pm 0.8 \mu \mathrm{m}$. The parasite cytoplasm presented granulations and deep staining. The nucleus was homogeneous and arranged perpendicularly to the longer axis of the parasite. In $76.1 \%$ of the parasites the nucleus was slightly displaced towards one of the extremities and in $23.9 \%$ it was in a central position. Its area was $13.9 \pm 2.6 \mu \mathrm{m}^{2}$, its length $5.1 \pm 0.5 \mu \mathrm{m}$ and its width $3.3 \pm 0.6 \mu \mathrm{m}$ (Fig. 1D). A "hook" was usually observed at one of the extremities of the parasite; (2) H. migonei, the smaller form was less elongated and more oval in shape. Its cellular area was $48.6 \pm 5.9 \mu \mathrm{m}^{2}$, its length $11.8 \pm 1.1 \mu \mathrm{m}$ and its width $5 \pm 0.6$ $\mathrm{mm}$. Its cytoplasm was homogeneous and lightly stained and contained a round and large nucleus in relation to the size of the parasite. In $52.5 \%$ of the parasites the nucleus was slightly displaced towards one of the extremities and in $47.5 \%$ it was in a central position. The area of the nucleus was $13.3 \pm 2.7 \mu \mathrm{m}^{2}$, the length was $4.5 \pm 0.6 \mu \mathrm{m}$ and the width $3.5 \pm 0.6 \mu \mathrm{m}$ (Fig. 1E). 
Comparative analysis of the various parasites Analysis of parasite area, length and width showed that the parasites of the various species had different dimensions ( $p<0.05)$, except for the length of Hepatozoon sp. of $C$. durissus terrificus and $H$. terzii (p > 0.05) (Table I). The various parasites also differed in terms of nucleus area and width $(p<0.05)$, except for $H$. philodryasi and $H$. terzii (p > 0.05) (Table I). The parasites showed two different patterns in terms of nuclear length: one shared by $H$. philodryasi, Hepatozoon sp. of $C$. durissus terrificus and $H$. cyclagrasi, and the other shared by the species $H$. terzi $i$ and H. migonei (Table I) . Multivariate analysis showed that the studied parasites can be divided into three different groups: one of them includes the species $H$. terzii, H. philodryasi and Hepatozoon sp. of C. durissus terrificus; and the other two consist of $H$. migonei and H. cyclagrasi (Fig. 2) .

Comparative analysis of infected and non-infected erythrocytes -Comparative analysis of infected and noninfected erythrocytes (t test) showed that the values obtained for $73.3 \%$ of the analyzed variables were significantly different $(\mathrm{p}<0.05)$ (Table II). We doserved that linear dimensions (nuclear or erythrocyte length and width) were different in 85\% of the cases, whereas area dimensions were different in only $50.0 \%$ of the cases (Table II) .
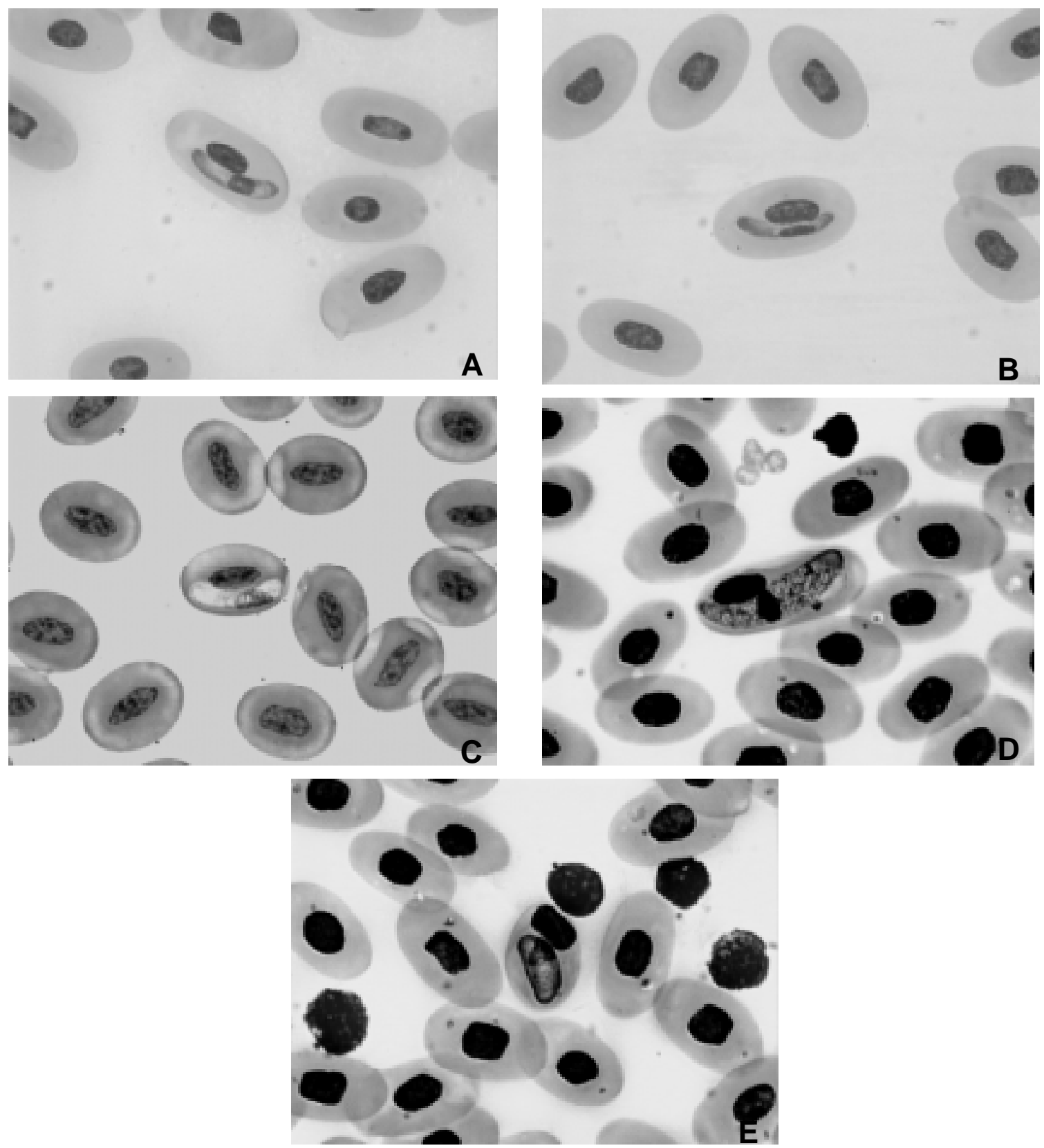

Fig. 1: gamont of Hepatozoon spp. in a blood smear. A: H. terzii from Boa constrictor amarali; B: Hepatozoon sp. from Crotalus durissus terrificus; C: H. philodryasi from Philodryas patagoniensis; D: H. cyclagrasi from Hydrodynastes gigas; E: H. migonei from H. gigas. Magnification, 1000x. 
TABLE I

Comparative analysis of the Hepatozoon species studied $(\mathrm{n}=100$ for each species)

\begin{tabular}{|c|c|c|c|c|c|c|}
\hline \multirow[b]{2}{*}{ Parasites } & \multicolumn{3}{|c|}{ Parasite } & \multicolumn{3}{|c|}{ Nucleus } \\
\hline & Area $\left(\mu \mathrm{m}^{2}\right)$ & Length $(\mu \mathrm{m})$ & Width $(\mu \mathrm{m})$ & Area $\left(\mu \mathrm{m}^{2}\right)$ & Length $(\mu \mathrm{m})$ & Width $(\mu \mathrm{m})$ \\
\hline H. terzii & $35.3 \pm 4.2 \mathrm{a}$ & $14.6 \pm 0.4 \mathrm{a}$ & $2.6 \pm 0.4 \mathrm{a}$ & $9.2 \pm 1.6 \mathrm{a}$ & $4.6 \pm 0.9 \mathrm{a}$ & $2.0 \pm 0.3 \mathrm{a}$ \\
\hline H. philodryasi & $37.5 \pm 7.2 \mathrm{~b}$ & $14.3 \pm 1.1 \mathrm{~b}$ & $2.8 \pm 0.5 b$ & $9.6 \pm 1.8 \mathrm{a}$ & $5.2 \pm 0.8 \mathrm{~b}$ & $2.0 \pm 0.4 \mathrm{a}$ \\
\hline Hepatozoon sp. & $33.2 \pm 4.1 \mathrm{c}$ & $14.7 \pm 0.6 \mathrm{a}$ & $2.4 \pm 0.4 \mathrm{c}$ & $8.5 \pm 1.7 \mathrm{~b}$ & $5.1 \pm 0.8 b$ & $1.7 \pm 0.4 b$ \\
\hline H. migonei & $48.6 \pm 5.9 \mathrm{~d}$ & $11.8 \pm 1.1 \mathrm{c}$ & $4.9 \pm 0.6 \mathrm{~d}$ & $13.3 \pm 2.7 \mathrm{c}$ & $4.5 \pm 0.6 \mathrm{a}$ & $3.5 \pm 0.6 \mathrm{c}$ \\
\hline H. cyclagrasi & $115.2 \pm 11.8 \mathrm{e}$ & $21.7 \pm 1.4 \mathrm{~d}$ & $6.4 \pm 0.8 \mathrm{e}$ & $13.9 \pm 2.6 \mathrm{~d}$ & $5.1 \pm 0.5 \mathrm{~b}$ & $3.3 \pm 0.6 \mathrm{~d}$ \\
\hline
\end{tabular}

The values presented in the Table represent the mean and the standard deviation for each variable; same letters in the columns represent $\mathrm{p}>0.05$; different letters in the columns represent $\mathrm{p}<0.05$.

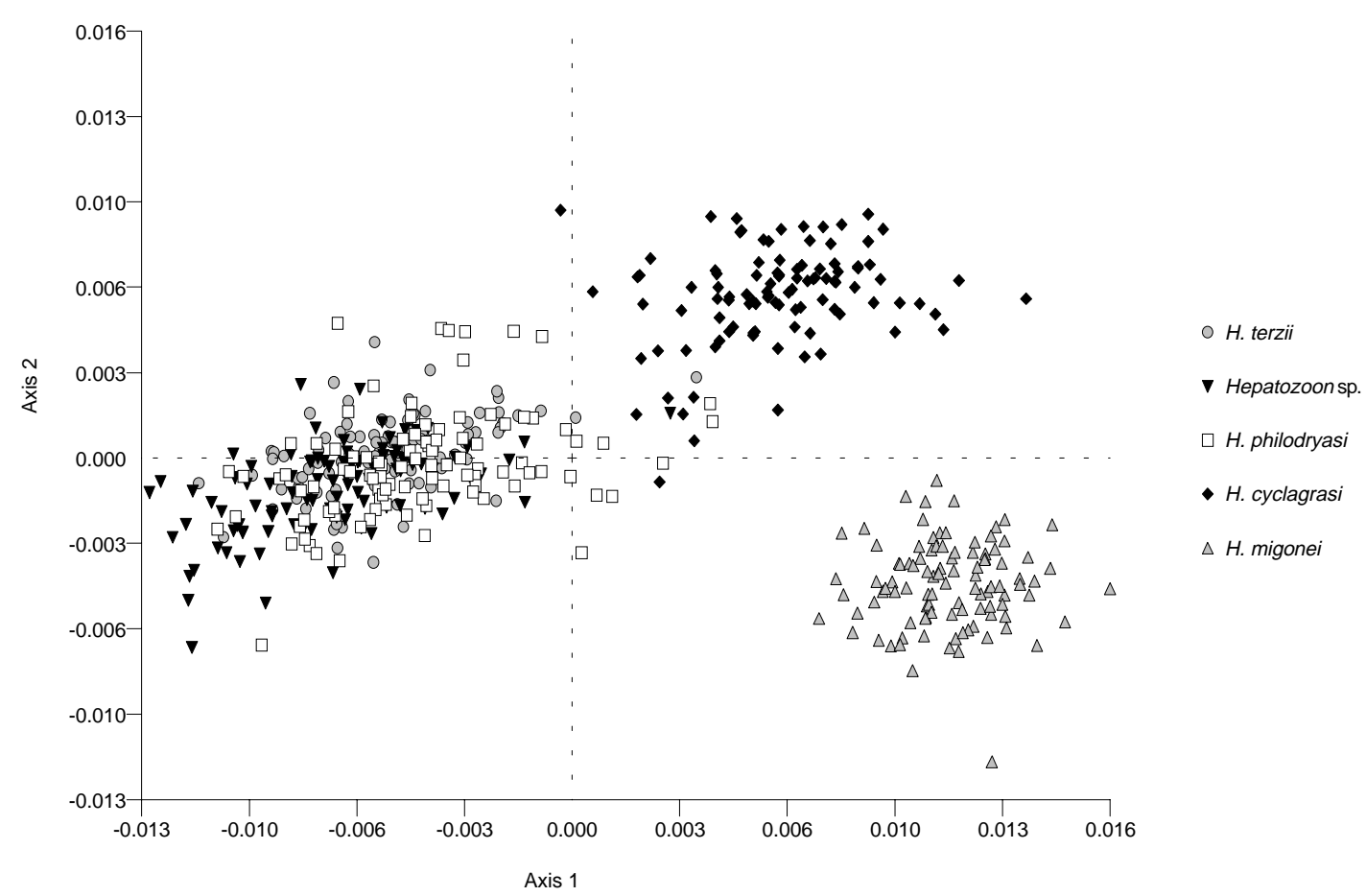

Fig. 2: multivariate analysis of the main components for comparison of the species of Hepatozoon studied. The values presented on the ordinate and abscissa axes represent the largest amount of variation in the data set.

Multivariate analysis, which was applied only to the linear variables, showed that $H$. cyclagrasi induced strong changes in erythrocyte morphology (Fig. 3). The changes in erythrocyte morphology induced by the species $H$. terzii, Hepatozoon sp. of C. durissus terrificus and by $H$. migone $i$ were less obvious than the changes induced by $H$. cyclagrasi (Figs 4, 5, 6). The changes induced by $H$. philodryasi were not evident (Fig. 7).

H. terzii, Hepatozoon sp. of C. durissus terrificus and $H$. philodryasi induced light flattening of the erythrocyte nucleus, which, however, was not dislocated to the cell periphery of. In contrast, $H$. cyclagrasi dislocated the erythrocyte nucleus to one of the poles in $55.5 \%$ of cases and laterally in $44.5 \%$, and also induced a marked deformation of the erythrocyte. H. migonei caused displacement of the erythrocyte nucleus to the poles in $63.1 \%$ of cases and laterally in $36.9 \%$. In spite of this displacement, the changes in the erythrocyte were less evident.

\section{DISCUSSION}

The objective of the present study was to evaluate the importance of morphology and morphometry for the characterization of Hepatozoon species that parasitize snakes. The dimensions and morphology of the five Hepatozoon species analyzed are in agreement with the description reported in the literature for those species. We evaluated linear and area data of the gamonts and submitted them to multivariate analysis, which permitted us to divide the species into three different populations (Fig. 2).

In most reports on Hepatozoon parasitizing snakes, new species were described on the basis of the length and width of the gamonts and schizonts and also of oocysts, sporocysts and sporozoites (Pessoa \& Biasi 1973). Also, in a recent review article it was reported that many Hepatozoon species were created by simply considering a new infected host (Smith 1996). 
The literature reports that exist immature and mature gamonts and that these developmental stages could be interpreted as different species (Smith 1996). Snakes with actively merogony may present gamonts of different sizes, with more slender forms representing an immature precursor to the larger gamonts (Smith et al. 1994). In the present paper, the specimens of the five studied species were homogeneous and the differentiation between mature and immature forms was not observed.
Some reports have demonstrated that the same Hepatozoon species can infect different hosts (Hull \& Camin 1960, Pessoa et al. 1971). Besides, the gamonts of a same species of Hepatozoon can present slight morphologic changes depending on the host. Pessoa et al. (1974) demonstrated that it was possible to transfer $H$. tupinambis of the lizard Tupinambis teguixin to the snake $C$. durissus terrificus. The transfer induced changes in the parasite so that in the lizard, Hepatozoon species produced eryth-

TABLE II

Comparative analysis of normal and parasitized erythrocytes of different snakes species

\begin{tabular}{|c|c|c|c|c|c|c|}
\hline \multirow[b]{2}{*}{ Parasites } & \multicolumn{3}{|c|}{ Cell } & \multicolumn{3}{|c|}{ Nucleus } \\
\hline & Area $\left(\mu m^{2}\right)$ & Length $(\mu \mathrm{m})$ & Width $(\mu \mathrm{m})$ & Area $\left(\mu m^{2}\right)$ & Length $(\mu \mathrm{m})$ & Width $(\mu \mathrm{m})$ \\
\hline \multicolumn{7}{|c|}{ Boa constrictor amarali } \\
\hline Normal & $161.3 \pm 16.1$ & $19.1 \pm 1.1$ & $10.2 \pm 0.7$ & $19.3 \pm 3.0$ & $6.1 \pm 0.9$ & $3.7 \pm 0.4$ \\
\hline Parasitized & $159.8 \pm 18.2$ & $19.7 \pm 1.2^{a}$ & $9.7 \pm 0.7^{a}$ & $20.0 \pm 2.8$ & $7.3 \pm 0.7^{a}$ & $3.2 \pm 0.5^{a}$ \\
\hline \multicolumn{7}{|c|}{ Crotalus durissus terrificus } \\
\hline Normal & $162.4 \pm 21.2$ & $18.9 \pm 1.3$ & $10.6 \pm 0.9$ & $24.2 \pm 3.9$ & $6.7 \pm 0.9$ & $4.3 \pm 0.5$ \\
\hline Parasitized & $172.9 \pm 27.0^{a}$ & $20.3 \pm 1.6^{a}$ & $10.4 \pm 1.1$ & $24.7 \pm 4.8$ & $7.6 \pm 0.8^{a}$ & $4.0 \pm 0.6^{a}$ \\
\hline \multicolumn{7}{|c|}{ Philodryas patagoniensis } \\
\hline Normal & $155.6 \pm 24.4$ & $17.5 \pm 2.3$ & $11.2 \pm 1.0$ & $23.4 \pm 3.6$ & $7.5 \pm 1.0$ & $4.0 \pm 0.7$ \\
\hline Parasitized & $167.6 \pm 19.0^{a}$ & $18.9 \pm 2.4^{a}$ & $11.2 \pm 1.1$ & $22.6 \pm 5.8$ & $7.7 \pm 0.8$ & $3.7 \pm 0.8^{a}$ \\
\hline \multicolumn{7}{|c|}{ Hydrodynastes gigas - larger parasites } \\
\hline Normal & $192.4 \pm 14.1$ & $20.7 \pm 1.1$ & $11.6 \pm 0.7$ & $33.2 \pm 3.9$ & $7.5 \pm 0.7$ & $5.4 \pm 0.5$ \\
\hline Parasitized & $187.9 \pm 21.9$ & $20.1 \pm 1.5^{a}$ & $11.9 \pm 1.3^{a}$ & $29.7 \pm 2.8^{a}$ & $7.3 \pm 0.6^{a}$ & $5.1 \pm 0.5^{a}$ \\
\hline \multicolumn{7}{|c|}{ Hydrodynastes gigas - smaller parasites } \\
\hline Normal & $192.4 \pm 14.0$ & $20.7 \pm 1.0$ & $11.6 \pm 0.7$ & $33.2 \pm 3.3$ & $7.5 \pm 0.6$ & $5.4 \pm 0.4$ \\
\hline Parasitized & $252.7 \pm 27.7^{a}$ & $25.4 \pm 1.5^{a}$ & $12.4 \pm 1.6^{a}$ & $26.8 \pm 4.4^{a}$ & $8.5 \pm 0.6^{a}$ & $3.9 \pm 0.5^{a}$ \\
\hline
\end{tabular}

$a$ : statistically significant differences in relation to normal erythrocytes.

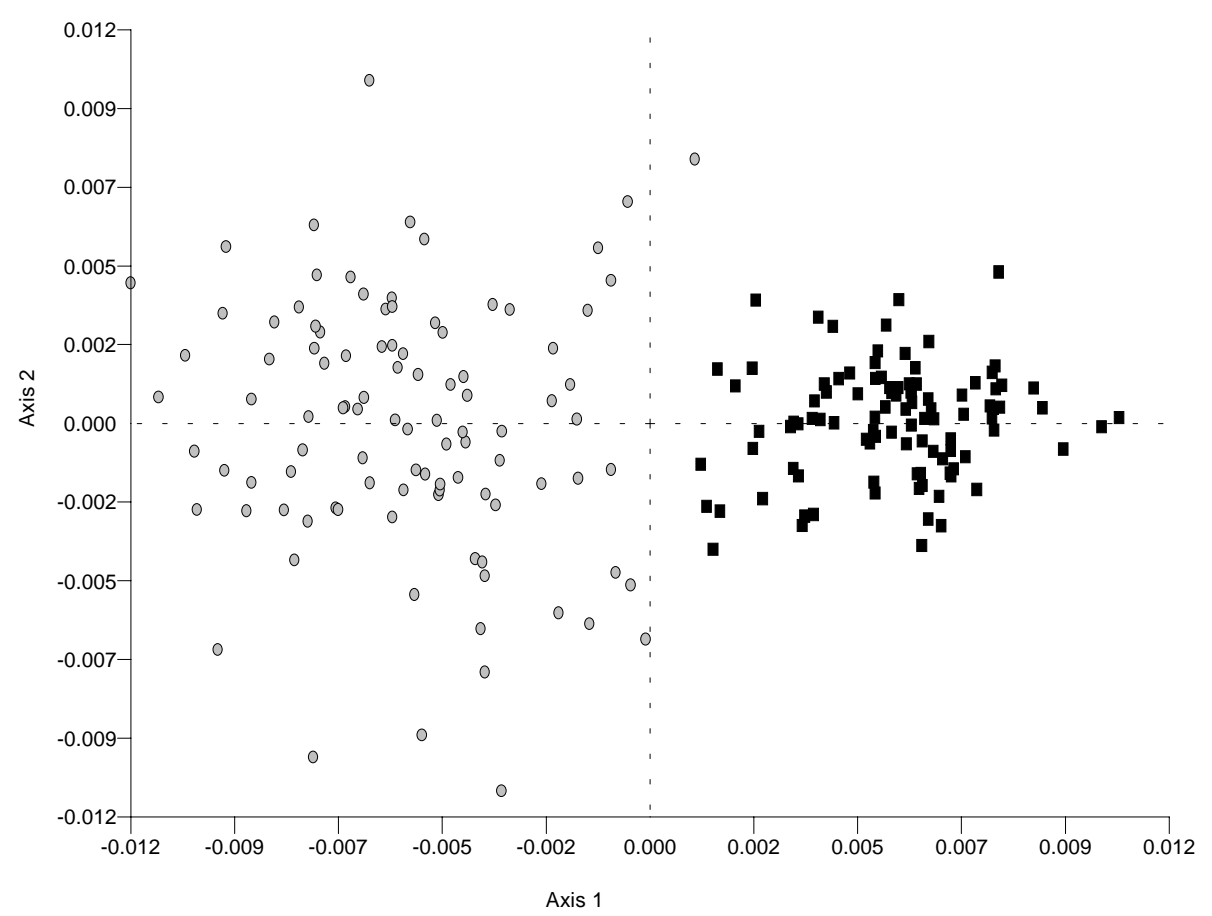

Fig. 3: multivariate analysis of the main components for comparison of normal erythrocytes $(\mathbf{\square})(\mathrm{n}=100)$ and erythrocytes parasitized $(\bullet)(n=100)$ by Hepatozoon cyclagrasi of Hydrodynastes gigas. The values presented on the ordinate and abscissa axes represent the largest amount of variation in the data set. 
rocyte deformations but this characteristic was gradually lost in the experimental infections.

The possibility that all of the Hepatozoon species described as parasites of terrestrial snakes, which are transmitted by mosquitoes, constitute a single species whose blood forms vary with the vertebrate host has also been discussed in the literature (Ball 1970, Pessoa et al. 1971).
The above considerations show that a controversy exists on this subject. Some investigators believe that several Hepatozoon species exist while others discuss the possibility that it is a single species presenting different morphologic patterns depending on the infected host (Smith 1996).

Our results show three different populations, support-

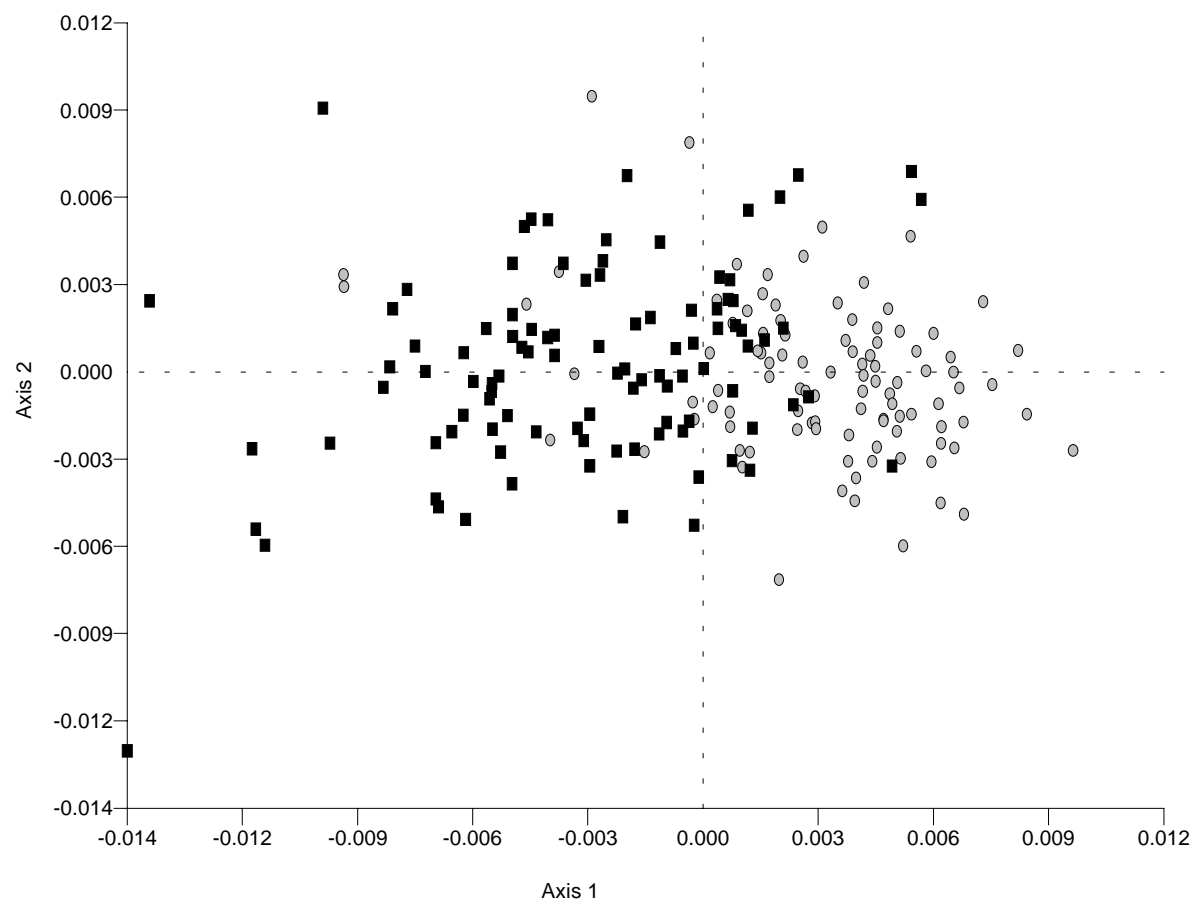

Fig. 4: multivariate analysis of the main components for comparison of normal erythrocytes $(\mathbf{\square})(\mathrm{n}=100)$ and erythrocytes parasitized $(\bullet)(n=100)$ by Hepatozoon terzii of Boa constrictor amarali. The values presented on the ordinate and abscissa axes represent the largest amount of variation in the data set.

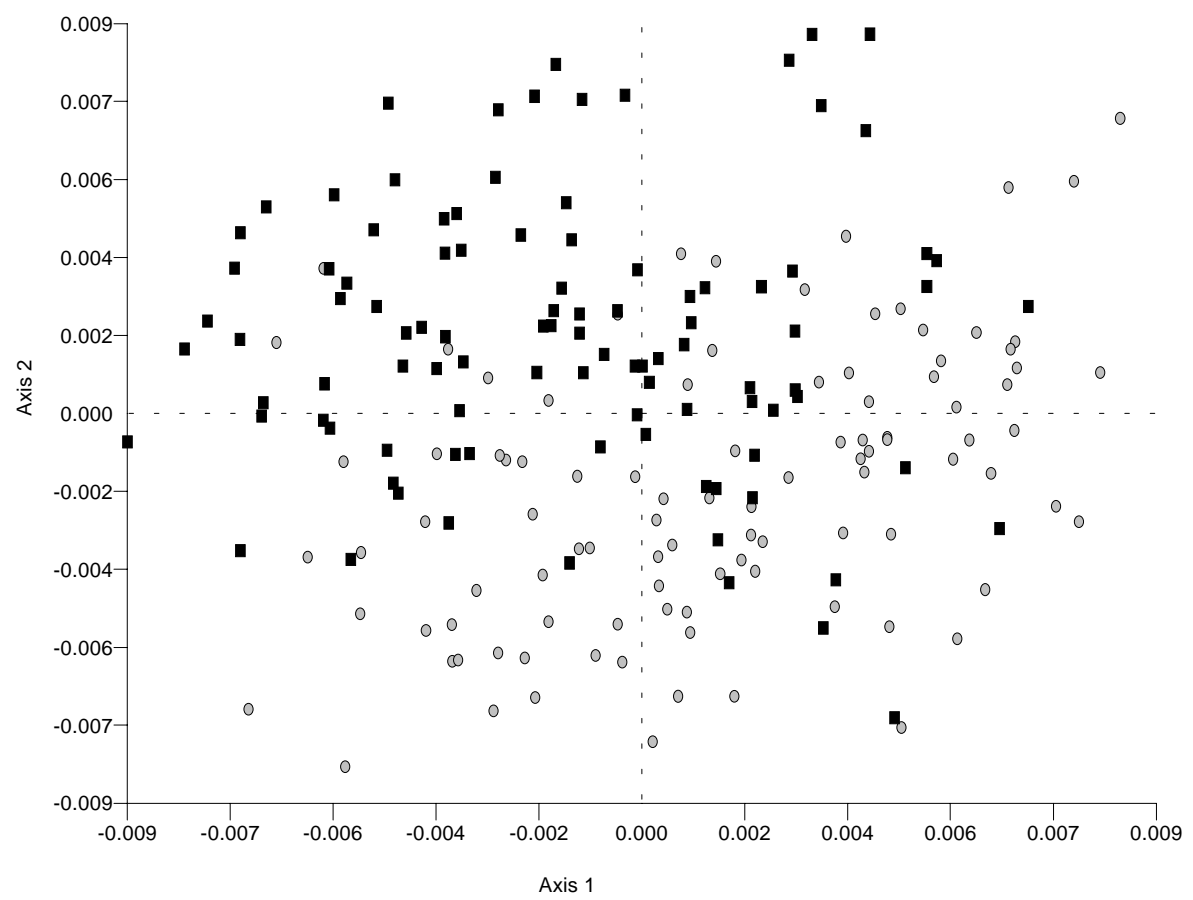

Fig. 5: multivariate analysis of the main components for comparison of normal erythrocytes $(\mathbf{\square})(\mathrm{n}=100)$ and erythrocytes parasitized (๑) $(\mathrm{n}=100)$ by Hepatozoon sp. of Crotalus durissus terrificus. The values presented on the ordinate and abscissa axes represent the largest amount of variation in the data set. 
ing the hypothesis of the existence of several species of Hepatozoon that can infect different species of snakes. The parasites found in $\mathrm{H}$. gigas are significantly different among themselves and the two are different from the other studied parasites.

By comparing the present results with those reported in the literature about the Hepatozoon parasites of the same snakes studied by us, we observe that disagreement exists about the determination of the species. Our results show that the gamonts of the species $H$. terzii, $H$. philodryasi and the Hepatozoon sp. of $C$. durissus terrificus do not differ morphologically, as shown in other reports describing these species (Sambon 1909, Carini 1910, Phisalix 1931).

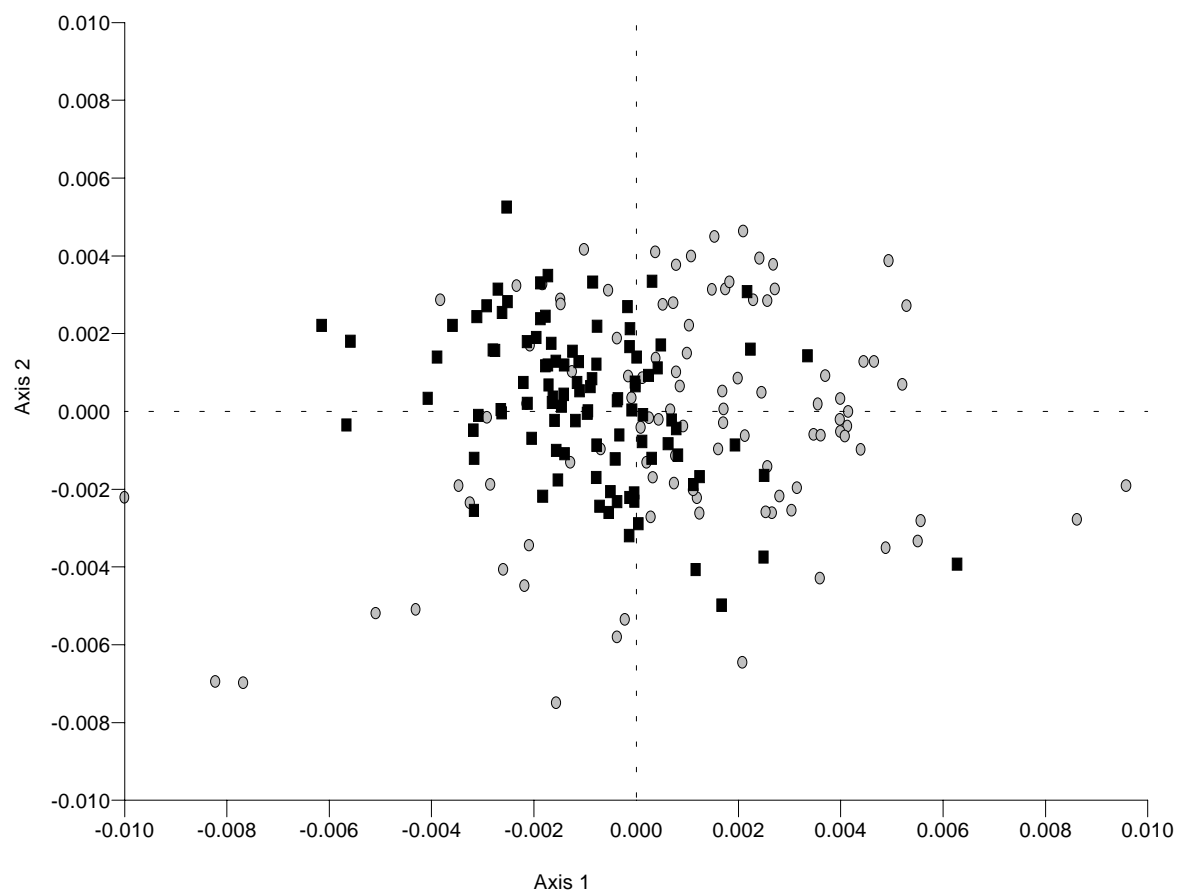

Fig. 6: multivariate analysis of the main components for comparison of normal erythrocytes $(\boldsymbol{\square})(\mathrm{n}=100)$ and erythrocytes parasitized $(\bullet)(\mathrm{n}=100)$ by Hepatozoon migonei of Hydrodynastes gigas. The values presented on the ordinate and abscissa axes represent the largest amount of variation in the data set.

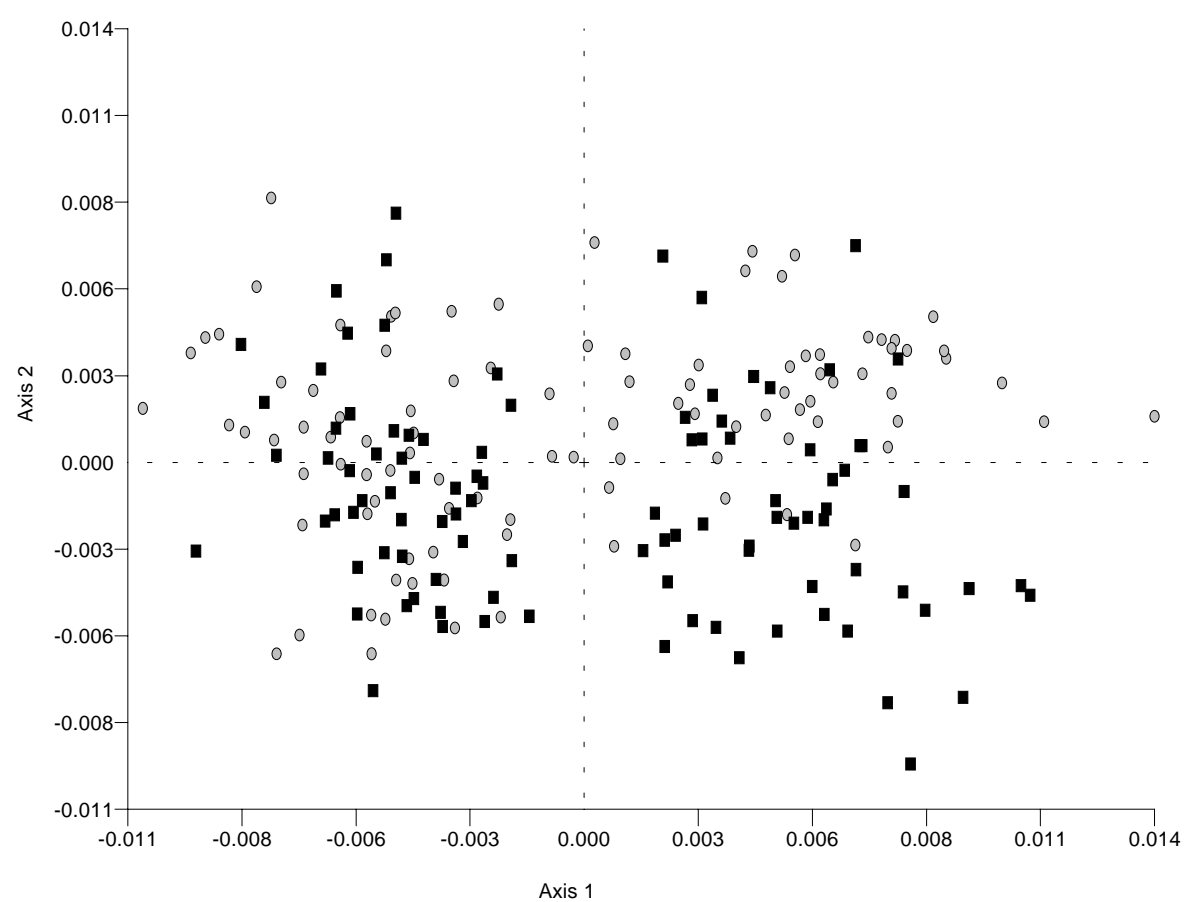

Fig. 7: multivariate analysis of the main components for comparison of normal erythrocytes $(\mathbf{\square})(\mathrm{n}=100)$ and erythrocytes parasitized $(\bullet)(\mathrm{n}=100)$ by Hepatozoon philodryasi of Philodryas patagoniensis. The values presented on the ordinate and abscissa axes represent the largest amount of variation in the data set. 
We also observed different patterns when we analyzed the changes induced in the erythrocytes by the parasites. We observed that all parasites induced changes, mainly in erythrocyte length, as well as nuclear flattening (Table II) and the changes induced by $H$. cyclagrasi were more pronounced, with alterations of the erythrocyte and its nucleus in terms of all of the parameters studied. $H$. migonei induced deformity of the length and width of the erythrocyte but not in its area. This parasite also caused a complete distortion of the nucleus, changing its length, width, area, and position. H. terzii did not modify the area of the erythrocyte or of its nucleus, but induced significant modifications in their lengths and widths. Hepatozoon sp. of $C$. durissus terrificus induced changes involving the area and length of the erythrocyte, and also flattening of the nucleus. H. philodryasi was the species that least modified the erythrocyte. Even so, it altered its area and the width of the nucleus.

The results obtained by morphologic evaluation showed that, depending on the considered variable, such as, for instance, area and width of the parasite, we can separate five different species, whereas for another variable, such as length of the nucleus, we can differentiate only two populations (Table I). Since we believe that the individual analysis of a variable is not sufficient to characterize a species, we submitted all the data obtained for each parasite to multivariate analysis, a procedure that permitted us to characterize only three different populations (Fig. 2).

Current knowledge does not allow us to state whether H. terzii, H. philodryasi and Hepatozoon sp. of C. durissus terrificus are a single species or whether they are closely related different species. This characterization may be obtained after analysis of sporogonic and esquizogonic stages also with the use of molecular techniques for comparison of the respective DNAs. If it is proven that these are only one species, the use of morphometry, a simple and inexpensive technique, will be of fundamental importance for the characterization of Hepatozoon species. However, if subsequent studies demonstrate that the species are different, the technique used by us cannot be used for species characterization, but can only be considered as an additional methodology for the study of this group, associated with morphologic studies of other evolutionary forms of Hepatozoon spp.

In the present study we did not evaluate other evolutionary forms of the parasites, which could contribute to a differentiation of populations. However, Smith (1996) reported that Hepatozoon sp. exhibit a high degree of plasticity for many features and therefore, morphological and morphometric features of the oocysts stage must be statistically significant in order for species to be described. Recent studies have demonstrated that identification using molecular techniques may contribute to solve this problem (Wozniak et al. 1994, Smith et al. 1999).

\section{REFERENCES}

Arantes JV 1934. Haemogregarina cyclagrasi n. sp. parasita da serpente Cyclagras gigas (Duméril e Bribon, 1854). Rev Biol Hyg S Paulo 5: 9.

Ball GH 1970. Hemogregarine life cycles. J Parasitol 56: 17.
Ball GH, Chao J, Telford Jr SR 1969. Hepatozoon fusifex sp. n., a hemogregarine from Boa constrictor producing marked morphological changes in infected erythrocytes. $J$ Parasitol 55: 800-813.

Carini A 1910. Sobre uma hemogregarina de Philodryas schottii. Rev Med S Paulo 23: 339-340.

Carini A 1947. Contribuição ao estudo das hemogregarinas de serpentes da família boídeos. Arq Biol 31: 61-63.

Hull RW, Camin JH 1960. Hemogregarines in snakes: the incidence and identity of the erythrocytic stages. $J$ Parasitol 46: 515-523.

Pessoa SB 1967. Notas sobre hemogregarinas de serpentes brasileiras. V: hemogregarinas da cascavel. Rev Bras Biol 27: 381-384.

Pessoa SB, De Biasi P 1973. Considerações taxonômicas sobre cistos esquizogônicos e sobre gametócitos de Hepatozoon (Sporozoa, haemogregarinidae) parasitas de serpentes brasileiras. Mem Inst Butantan 37: 291-298.

Pessoa SB, De Biasi P, Puorto G 1973. Nota taxonômica sobre cistos esporogônicos de algumas espécies de Hepatozoon (Sporozoa, Haemogregarinidae) parasitas de serpentes brasileiras. Mem Inst Butantan 37: 299-307.

Pessoa SB, De Biasi P, Puorto G 1974. Transferência do Hepatozoon tupinambis, parasita do lagarto Tupinambis teguixin, para a serpente cascavel (Crotalus durissus terrificus) por intermédio de mosquito Culex fatigans. Mem Inst Oswaldo Cruz 72: 295-299.

Pessoa SB, Saccheta L, Cavalheiro J 1970. Notas sobre hemogregarinas de serpentes brasileiras. X: Hemogregarina de Hydrodynastes gigas (Duméril et Bibron) e sua evolução. Rev Lat-amer Microbiol 12: 197-200.

Pessoa SB, Belluomini HE, De Biasi P, De Souza DM 1971. Notas sobre hemogregarinas de serpentes brasileiras. XIV Esporogonia da hemogregarina da Bothrops moojeni Hoge, 1965 no Culex (Culex) dolosus, (L. Arribálzaga, 1891). Arq Inst Biol São Paulo 38: 253-258.

Phisalix M 1931. Les hémogrégarines de Crotalus terrificus Lau. Bull Soc Path Exot 24: 190-194.

Sambon W 1909. The hemogregarines of snakes. J Trop Med Hyg 12: 48-55.

Schouten GB 1934. Haemogregarina migonei $\mathrm{n}$. sp. hematozoário de ofídio, Cyclagras gigas D e B. Rev Soc Cient Paraguay 3: 145-157.

Silva RJ, Takahira RK, Cherubini AL, Bianchi EH, Barrella TH, Martins GTB, Ferreira Jr RS, Cordeiro AV, Lopes CAM 1999. Análise morfométrica de Hepatozoon encontrado em Boa constrictor amarali (STULL, 1932) (Serpentes, Boidae). In $1^{\circ}$ Congresso Brasileiro de Conservação e Manejo da Biodiversidade, Ribeirão Preto, SP, p. 29-30.

Smith TG 1996. The genus Hepatozoon (Apicomplexa: Adeleina). J Parasitol 82: 565-585.

Smith TG, Desser SS, Martin DS 1994. The development of Hepatozoon sipedon $\mathrm{n}$. sp. (Apicomplexa: Adeleina: Hepatozoidae) in its natural host, the Northern water snake (Nerodia sipedon sipedon), the culicine vectors, Culex pipiens and Culex territans, and an intermediate host, Northern leopard frog (Rana pipiens). Parasitol Res 80: 559-568.

Smith TG, Kim B, Desser SS 1999. Phylogenetic relationships among Hepatozoon species from snakes, frogs and mosquitoes of Ontario, Canada, determined by ITS-1 nucleotide sequences and life-cycle, morphological and developmetal characteristics. Int J Parasitol 29: 293-304.

Wozniak EJ, Telford SR, McLaughlin GL 1994. Employment of the polymerase chain reaction in the molecular differentiation of reptilian hemogregarines and its application to preventative zoological medicine. J Zoo Wildl Med 23: 538-547. 